\title{
An English Learning Method Based on Computer-assisted System
}

\author{
https://doi.org/10.3991/ijet.v12i02.6045 \\ Jingyi Bo \\ Hebei Normal University of Science\& Technology, Qinhuangdao, Hebei, China \\ qhdbjy@126.com \\ Yubin Wang \\ Hebei Normal University of Science\& Technology, Qinhuangdao, Hebei, China \\ qhdwyb@126.com \\ Kun Han \\ Hebei Normal University of Science\& Technology, Qinhuangdao, Hebei, China \\ hankunkun@ $126 . \mathrm{com}$
}

\begin{abstract}
Computer terminology is studied by unit, professional computer knowledge and lexical features, etc. in this paper. An effective game-based learning pattern is generated combined with the characteristics of computer English terms. The computer-assisted English learning system is studied to help students memorize terminology. This learning system could also examine the learning effect after study. The relevant question bank is available to users for game-based examination. The examination result and the statistic score could be kept in the question bank for analysis of the learning effect.
\end{abstract}

Keywords-English learning system, Computer-assistant education, Computer technology, Software development

\section{Introduction}

The teaching purpose of professional computer English is to train students to master commonly used computer English vocabulary and develop the reading, understanding, translating and writing skills of technology English. However, this subject is designed as the optional course in universities and colleges where the learning effect for many students can be obviously seen from the translated professional foreign literature in graduation design and English abstracts of graduation theses. Some students even directly use the translation software such as "King soft Fast AIT" [1]. How to better teach professional computer English and realize better teaching and learning effects is the issue for many computer teachers for discussion. It is common that stu- 
dents do not have high interest in learning professional English in current teaching methods, for various reasons. Firstly they are not clear for the purpose of courses and teaching targets, and some students with poor English think that professional English is nothing more than an extension of public English and you can get a high score in the examination as long as you instantly memorize the terminology. Unclear study targets result in non-emphasis on professional English courses. Secondly, for students with poor English, too much terminology, complicated long sentences and complex word formation makes study of professional English more difficult, to the point that they may lose confidence in the study or even finally abandon it [2].

\section{Students Misunderstanding for English Learning with Computer}

Students' ignorance of the importance to study computer English: Computer English is usually thought to be an independent course and its role as a tool cannot be reflected in the course. For example, some students think that it is only useful in translating the abstract of a graduation thesis, or even think that they do not have the opportunity to access foreign literature until after they start work. However, having carefully observed our usual teaching of professional computer English, we can find that the use of professional computer English is very common, and that it is widely used in everything from system commands to computer programming.

Students have no interest in learning computer English: It is common that most students do not have high interest in learning computer English. It is boring to mechanically memorize English words, the introduction of an interesting game for learning would be effective in this area. The great scientist Einstein once said: "interest is the best teacher." Stimulating students' learning interest is one of the best ways to improve the teaching quality during the teaching process. During the teaching process, the learning efficiency could be improved by inducing students' learning motivation and stimulating their learning efficiency, thus to apply what they have learned into practice [3].

Students usually ignore the context in learning computer English vocabulary: It is well-known that memorizing words is very important for language study. In memorizing the fundamental English vocabulary, almost every English teacher emphasizes the importance of the context; i.e., that only by combining the new word with a specific application context can be effective [4]. The context is also very important in remembering computer terminology. However, students often ignore the importance of context during their learning.

\section{$3 \quad$ Data Mining}

Along with the development of modern information technology, computer technology has become the most important technology in the present day. The development of internet technology results in increasingly great competition and pressure for all 
kinds of professions as well as in personal life, and people are forced to have more efficient working capability to improve their study and work efficiency. Meanwhile, a large amount of data is generated and accumulated in servers and computers. In order to survive in the intense competition, enterprises have gradually established their own information department to achieve various businesses endeavors through computer networks with large amounts of data regarding products, clients, raw materials, personnel and market, etc. all stored in their own computers. Even scientific research institutions and government departments have also begun the digital transformation [5]. However, faced with such vast amounts of data, it is impossible to only depend on manpower to find the critical information needed to guide the company or government out of billions of pieces of data. Only data mining technology can be applied to find the useful information. To be simple, it is the process of extracting the valuable knowledge from a large amount of data. Now, there are many definitions for data mining and below is the common definition.

\subsection{Determining The Data Source Object}

It is the first step and also the most important step to make the purpose of data mining clear and to recognize the data source object of data mining [6]. If at the very beginning the data mining object is not clear, the result cannot definitely satisfy its requirement. Although mining results has many uncertainties, there is at least the direction that must be specified. Therefore, it is a very important step to determine the data source object [7].

\subsection{Determining The Target Data}

After the data source object has been determined, the target data is taken out for mining. However, not all data source objects are useful target data, because errors exist in data input for various reasons when the original data is input into data bank, such as manager's errors or computer errors during the input process, etc. [8]. In order to avoid errors in the later mining work without subject to the erroneous data, exclusion work is necessary in selecting target data to exclude obvious erroneous data [9].

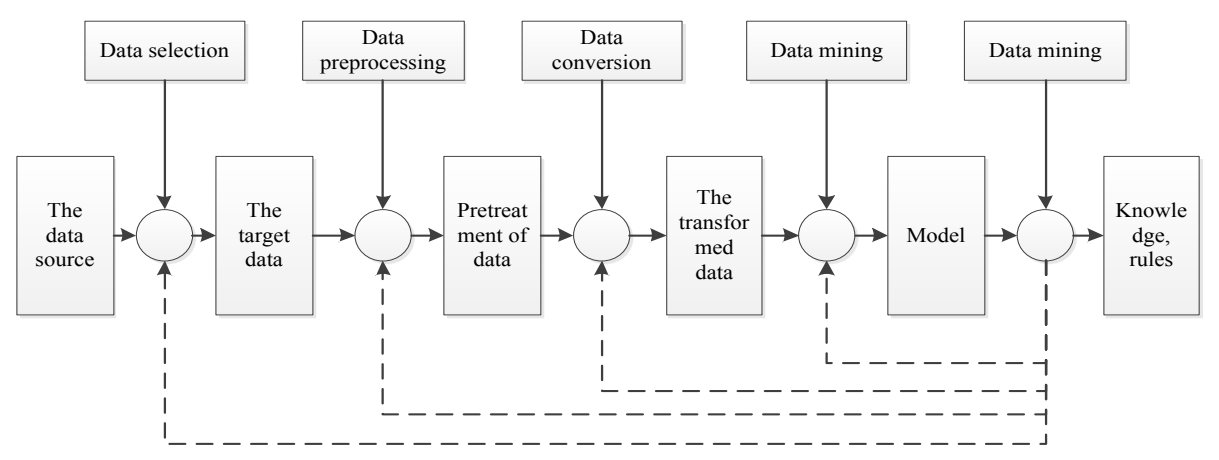

Fig. 1. The flow chart of data mining 


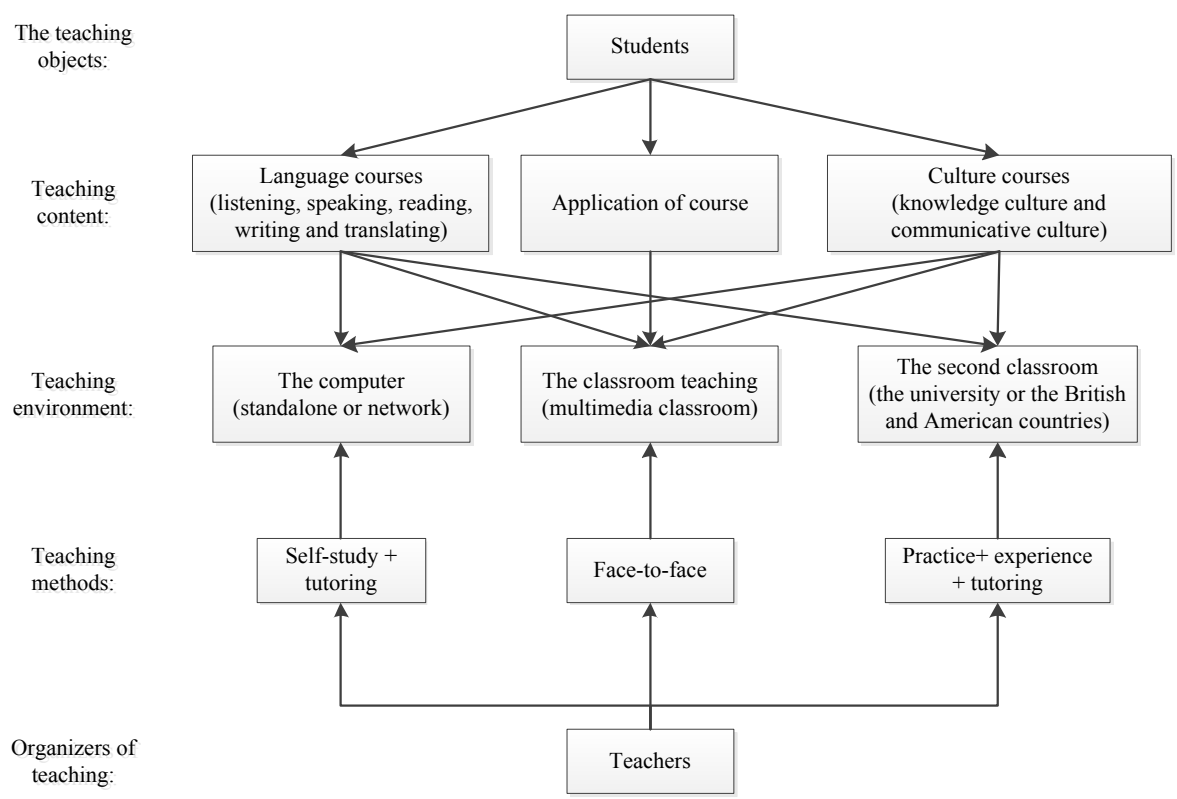

Fig. 2. University English teaching mode and cross-cultural communication exchange program

\subsection{Pretreatment and Data Conversion}

After determining target data and before the actual mining work, the received target data will be applied in the algorithm for primary processing of data. The original data cannot be computed. For example, a student's core is usually a hundred-mark system but there are only three to four classification types of students in data mining. The student's examination score needs to be transferred from a hundred mark system into the classification type of data mining.

\subsection{Generational pattern}

The core step of data mining is the process to take and select the algorithm, determine the parameters and make the implementation for the pattern. The purpose of data mining is to help people understand a large amount of original data by finding the meaningful pattern. Since problems to be resolved are different and data emphasis is different, the generated pattern is also different so that there is strong connection between the pattern and the question.

\subsection{The Rule of Generation}

Having the above generated pattern does not mean successful mining because the pattern may be meaningless, not practical or even opposite. We must make verifica- 
tion and evaluation of the generated pattern to determine whether data mining has deviated or the result is correct. After the verification is completed, we can obtain the correct rule to guide our data analysis, shown in Figure 1.

\section{Overall Design of Learning System}

A word bank or article bank in a learning system is a comprehensive resource bank for computer English, including computer hardware, software, figure, multimedia technology, internet, communication and office application, etc. The learner can select applicable learning scope based on their specialty, or the learning target and relevant task is generated according to the learning target; i.e., game-based learning of the word bank and article learning by units.

Game-based learning of a word bank starts from the low difficulty level, then it is distributed by lexical features, lexical classification and difficulty level, etc. It is suggested to start from the low difficulty level. For erroneous vocabulary, its appearance frequency is set high and the system will design a learning cycle according to the remembering-forgetting curve. So the learning effect will be better when the learner follows the learning cycle in the game software. The learning status during the learning process will be recorded to give the learning suggestion for the next step and the system will automatically record the relevant operation log.

Article bank learning starts from Unit 1 of a learner's teaching material, and the learning plan could be adjusted according to the importance and difficulty of articles. The terminology in the article will be automatically explained from the word bank. The learning time for each article is limited and if not completed, it is not allowed to skip to the next; otherwise, it is invalid for learning of this article. This means that all learning notes for this article and learning records in the system will not be used for analysis of the learner's features. The learner could concurrently utilize game-based learning of the word bank and article learning by units. The effect will be better if the learner previews and reviews vocabulary in the article in tha game scene while learning the article and learning the lexical context in the article while learning the vocabulary, as shown in Figure 2.

\subsection{Realization of Lexicon}

In collecting the vocabulary, to the word bank collects as much computer terminology as possible. After the classification and standardization process, the word bank can be applied in learning and testing. However, the amount of computer vocabulary is very large, or there may be errors in the original data or errors made in the vocabulary classification in the collection process, particularly for three indexes of difficulty coefficient, appearance frequency and importance level. However, since the computer updates quickly, computer English is also constantly developing and new words will continuously appear. So, after the word bank is established, the system still needs to maintain the word bank, as shown in Figure 3 


\subsection{Realization of Question Database}

The question bank needs to consider the quality, quantity, classification theory for target level, question type and proposition technology theory, etc. It must also consider how to intellectually assess examination papers. So the optional question types in the system are include one-choice questions, multiple-choice questions, true or false questions and gap filling. During word bank realization, beside the question itself, many indexes are also available including question source, knowledge, answer and notes, difficulty, normal answer time, similar questions and use situation (accuracy and average answer time). Those parameters are placed in the word bank in a specified structure, shown in Figure 4.

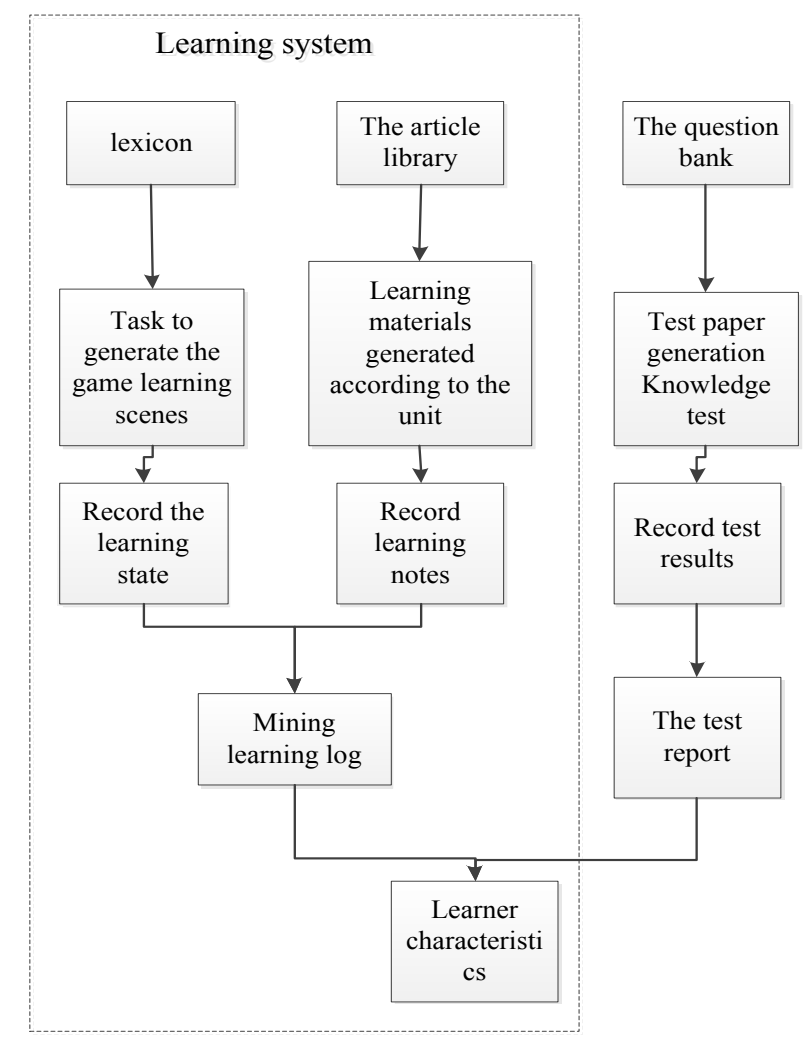

Fig. 3. Learning system overall design

\subsection{Realization of Article Library}

Article bank refers to the collection of scientific and technological articles with learning value. The article bank realization is to select teaching articles of computer English, notes for terminology and contract study in Chinese and English browsing 
methods. In order to enrich the article bank and closely follow the cutting-edge of IT technology, the system also must check academic literature both in English and Chinese closely related to computer English, noting important terminology in the article and indicating in both Chinese and English examples of use of this terminology in context. Combined with teaching requirements, it aims to improve the system's support for teaching. The reference interface for article realization is shown in Figure 4. Article population includes article title, article content and the translation, also difficulty setup and applicable specialty setup. The level of difficulty of an article is divided into simple, general, difficult and hard. The applicable specialty setup by professional knowledge is divided into computer communication, computer application, computer software, computer scientific education, software engineering, computer hardware (device and equipment), computer network, computer multi-media, computer information management, computer system maintenance, graph picture production, animation design and production, computer network and safety management, website planning and development, game software, software development and program management, advertising media development, three-dimensional animation design, computer music production, software test and built-in technology and application, etc. show in Figure 5.

The contrast class adopts a traditional teaching method. In the classroom, we explain the articles by using a traditional recorder+blackboard and grammar-translation methods. The teacher will lead the students to read the new words in order to make sure they grasp the accurate pronunciation. Then comes the explanations of difficult words, grammar, key phrases and structures, and many examples will be used for illustration. The teacher will again translate every sentence of the article so that the student can acquire a more accurate and deeper understanding of every word and sentence in the article. The main task in the classroom is to listen carefully and take regular notes and practice Chinese-English or English-Chinese translations of the sentences in the book or the examples proposed by the teacher, and sometimes the

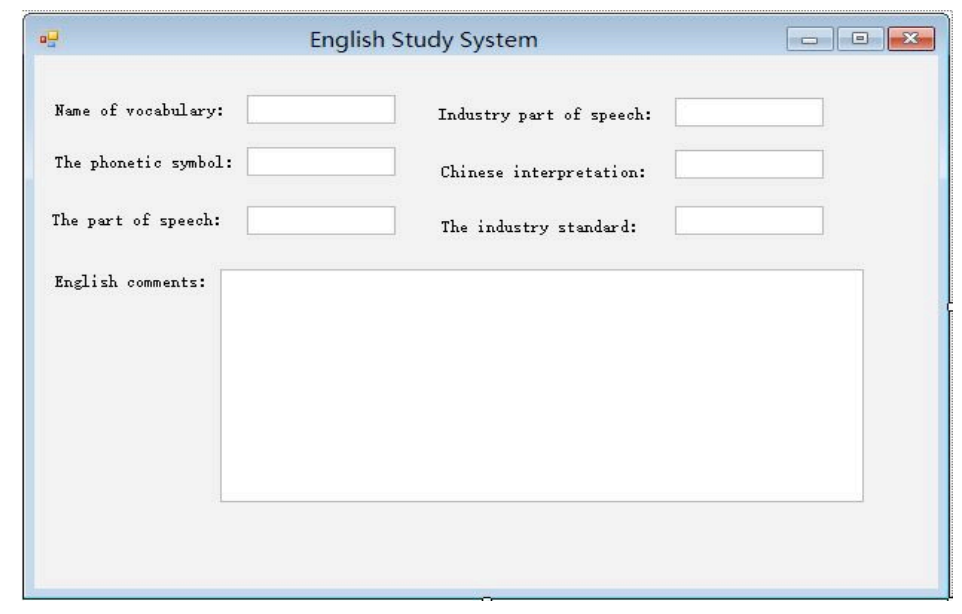

Fig. 4. Learning system overall design 
student will answer the questions raised. That is, the classroom teaching activity is conducted with the teacher as the center and the student must closely take in the knowledge taught by the teacher. Under this method, the student has fewer opportunities to participate actively in the teaching activities, so only a few take the initiative. Most of them are afraid of speaking for the fear of making mistakes or due to a poor foundation. The homework are the exercises in the book which are mainly to consolidate the words, phrases and sentences learned. The chances for students to speak or refer to materials are rare, as all of these tasks are performed by the teacher.

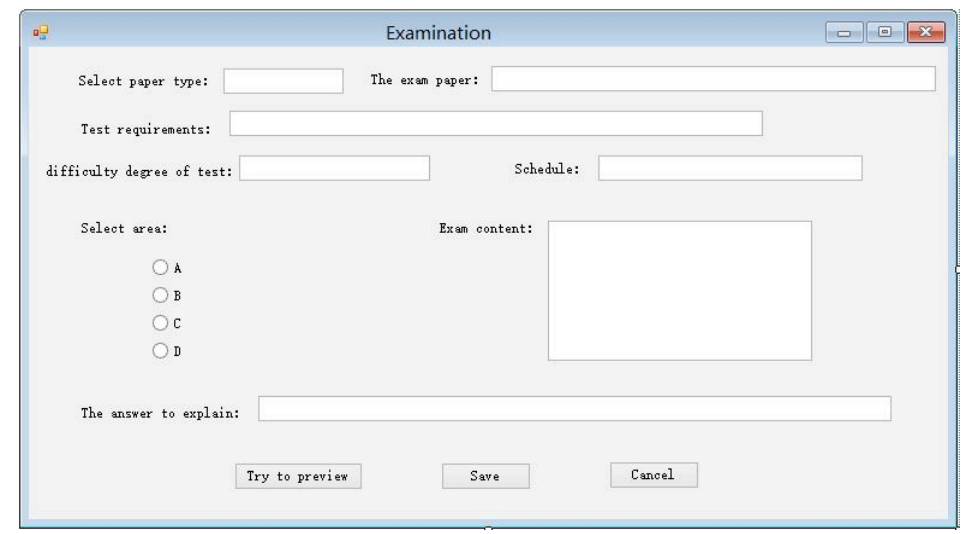

Fig. 5. Learning system for examination

\section{Conclusions}

A computer-assisted English learning system is comprehensively introduced in this paper and the key technologies in the system have been researched and improved. Compared with the traditional educational training method, game-based learning has more abundant modes of presentation, enabling users to learn the theory knowledge in entertaining ways, and learners can complete the learning target and task with regular examinations and automatic paper inspection. The Visual Studio 2008(C\#) integrated development environment realizes each function in the system and provides users friendly man-machine interaction and game-based learning. The work in this paper is summarized as below.

1. Research data collection algorithm. The withdrawal technology of content on the website is applied and improved to firstly analyze lexical characteristics starting from the perspective of common English, then to classify computer English vocabulary by specialty, and to collect and summarize vocabulary of game-based learning software according to the knowledge structure. Then the vocabulary is adjusted according to the difficulty coefficient, which is readjusted according to the vocabulary in word bank, article bank and examination process, thus to enhance its practi- 
cal significance and guarantee the realization of a follow-up learning system and a test system, shown in table 1.

2. Research data mining technology. Learners keep relevant records of much value during the learning process, and also meaningless data interference. Multi-step processing will transfer the records of many learners into regular data with reference value, and then make an evaluation for the learning effect by study times and days to propose improvements in the learning process of computer English learning.

3. Complete design and realization of the computer-assisted English learning system. Starting from the existing problems in the teaching of computer English, the importance of computer English vocabulary in computer English study is analyzed and, it is described in the application of human's memorizing-forgetting curve in lexical study, shown as table 2. From the establishment of a word bank, question bank, article bank and the relevant system realization of the overall design of the learning system, computer English learning methods are proposed to learners by applying game-based learning and a test system. Compared with the traditional learning method, the learning effect of computer English vocabulary is obviously improved.

Table 1. College English teachers' computer level aspects of the relevant information

\begin{tabular}{|c|c|c|c|}
\hline Project & Choose the answer & Number & Percent (\%) \\
\hline \multirow{4}{*}{ Do you have a computer } & Already have & 78 & 75 \\
\hline & Intend to buy as soon as possible & 15 & 15 \\
\hline & Take a look at again & 23 & 23 \\
\hline & Don't plan to buy & 1 & 1 \\
\hline \multirow{4}{*}{$\begin{array}{l}\text { What do you think of their } \\
\text { computer level }\end{array}$} & Poor & 5 & 2 \\
\hline & General & 3 & 3 \\
\hline & Good & 22 & 22 \\
\hline & Very good & 21 & 21 \\
\hline \multirow{10}{*}{$\begin{array}{l}\text { Your computer is obtained } \\
\text { through what channels }\end{array}$} & Did not take part in & 14 & 15 \\
\hline & The title test & 10 & 9 \\
\hline & Computer grade examination (level 1) & 2 & 2 \\
\hline & The computer rank examination (level 2) & 5 & 5 \\
\hline & Other & 64 & 60 \\
\hline & Learn at school & 78 & 79 \\
\hline & On-the-job training & 21 & 21 \\
\hline & Self-study & 16 & 15 \\
\hline & Day release & 3 & 4 \\
\hline & The other way & 9 & 10 \\
\hline \multirow{4}{*}{$\begin{array}{l}\text { Do you have to improve } \\
\text { their computer level }\end{array}$} & Very urgent & 1 & 1 \\
\hline & Urgent & 48 & 40 \\
\hline & It doesn't matter & 20 & 18 \\
\hline & No need & 17 & 14 \\
\hline
\end{tabular}


Table 2. Students learning condition with computer technology

\begin{tabular}{|c|c|c|c|c|}
\hline & & $\begin{array}{c}\text { Teacher } \\
(\%)\end{array}$ & Student (\%) & $\begin{array}{l}\text { The average attitude of } \\
\text { teachers and students } \\
(\%)\end{array}$ \\
\hline \multirow{8}{*}{$\begin{array}{l}\text { Teachers' } \\
\text { interpretation } \\
\text { of the multi- } \\
\text { media class- } \\
\text { room }\end{array}$} & Knowledge transmitter & 63.5 & 80.3 & 71.6 \\
\hline & Needs analyst & 42.3 & 84.1 & 60.2 \\
\hline & Student collaborators & 36.2 & 62.3 & 65.3 \\
\hline & The direction of the guide & 51.2 & 74.3 & 61.3 \\
\hline & Planners & 23.4 & 81.3 & 53.6 \\
\hline & Motivation to inspire people & 23.9 & 23.6 & 23.6 \\
\hline & Knowledge training & 51.3 & 25.9 & 30.6 \\
\hline & Academic evaluation & 12.6 & 28.6 & 20.3 \\
\hline \multirow{8}{*}{$\begin{array}{l}\text { Students } \\
\text { network } \\
\text { autonomous } \\
\text { learning } \\
\text { environment }\end{array}$} & Knowledge transmitter & 52.1 & 29.6 & 31.9 \\
\hline & Needs analyst & 12.6 & 35.1 & 25.9 \\
\hline & Student collaborators & 23.5 & 38.6 & 25.4 \\
\hline & The direction of the guide & 28.3 & 31.5 & 29.9 \\
\hline & Planners & 23.6 & 37.6 & 31.2 \\
\hline & Motivation 46 to inspire people & 2.5 & 38.2 & 19.8 \\
\hline & Knowledge training & 25.8 & 62.1 & 41.6 \\
\hline & Academic evaluation & 41.6 & 62.9 & 50.1 \\
\hline
\end{tabular}

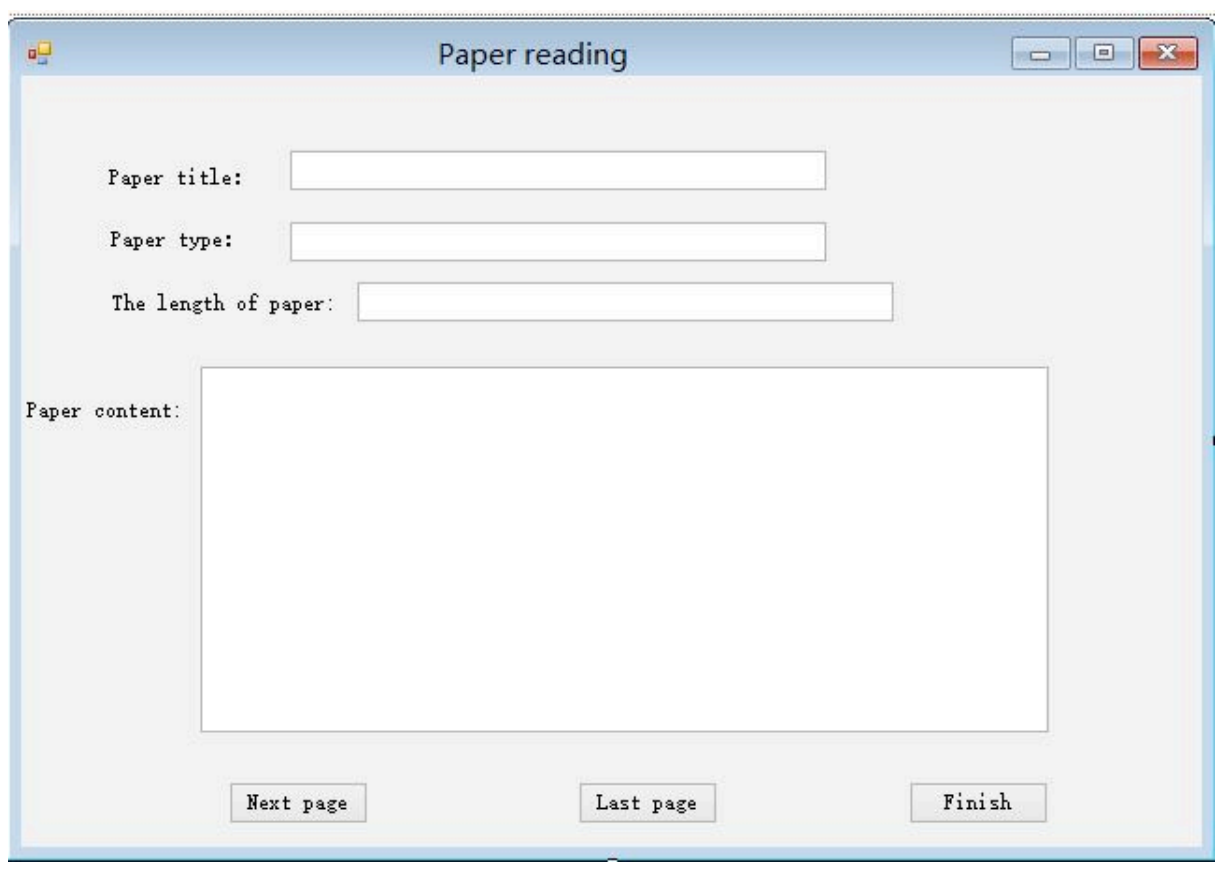

Fig. 6. Learning system for paper reading 


\section{References}

[1] X. Chen, Application of Computer Aided Instruction (CAI) in English teaching for nonEnglish-major postgraduates based on constructivism. Advances in Intelligent and Soft Computing, Vol. 140, pp. 205-210, April 2012. https://doi.org/10.1007/978-3-642-27945432

[2] Y. Chen, The application of multimedia computer assisted language learning in English teaching. Advanced Materials Research, Vol. 9, pp. 4634-4637. May 2014. https://doi.org/10.4028/www.scientific.net/amr.926-930.4634

[3] M. Haitao, Computer-based student-centered classroom in English language teaching. BMEI 2011 - Proceedings 2011 International Conference on Business Management and Electronic Information, Vol. 2, pp. 714-717, June 2011. https://doi.org/10.1109/icbmei.2011.5918012

[4] J. Li, Y. Li, Computer education for Chinese College English teachers: Time to take action. ICCSE 2010 - 5th International Conference on Computer Science and Education, Final Program and Book of Abstracts, ICCSE 2010, pp. 306-311.

[5] S. Li, Multimedia computer assisted instruction in college English teaching. Proceedings4th International Conference on Computational and Information Sciences, ICCIS 2012, pp. 754-757.

[6] B. Shi, Empirical research on feasibility and effect of computer-aided College English teaching model. Proceedings-2009 International Conference on Information Engineering and Computer Science, ICIECS 2009, pp. 258-261. https://doi.org/10.1109/iciecs.2009.5362868

[7] R. Sun, Analysis of teacher role in computer-based English teaching. Communications in Computer and Information Science, Vol. 267, pp. 458-463, August 2012. https://doi.org/10.1007/978-3-642-29084-8 71

[8] X. Tang, Integrating computer technologies into College English Teaching in China. 2010 International Conference on E-Health Networking, Digital Ecosystems and Technologies, EDT 2010, 371-374.

[9] C. Barbaranelli, L. Petitta, T.M. Proust, Does safety climate predict safety performance in Italy and the USA? Cross-cultural validation of a theoretical model of safety climate, Accident Analysis and Prevention, Vol. 77,pp. 35-44, April 2015. https://doi.org/10.1016/j.aap.2015.01.012

[10] V. Evers, Cross-cultural applicability of user evaluation methods: A case study amongst Japanese, North-American, English and Dutch users, Conference on Human Factors in Computing Systems - Proceedings, 2002, pp. 740-741.

[11] Z. Guo, Analysis on cross-cultural factors on English translation, Lecture Notes in Electrical Engineering, Vol. 207, pp. 759-764, May 2013. https://doi.org/10.1007/978-1-44714793-0 97

[12] E. Knight, C. Gunawardena, F. Bouachrine, A cross-cultural study of icons and images used in North American web design, WIT Transactions on Information and Communication Technologies, Vol. 36,pp. 135-144, 2006. https://doi.org/10.2495/is060141

[13] B. Liang, Cross-cultural awareness in college English teaching, Applied Mechanics and Materials, Vol. 599.pp. 2011-2013, August 2011.

[14] J. Wu, Based on the cross-cultural perspective of the change of English teaching research in China, Proceedings - 2015 International Conference on Intelligent Transportation, Big Data and Smart City, ICITBS 2015, pp. 164-168. https://doi.org/10.1109/icitbs.2015.47

[15] M. Tina, Application of computer multimedia technology on English teaching. WIT Transactions on Engineering Sciences, Vol. 87, pp. 947-952, August 2014. 
[16] Y. Wang, Research on human-computer interaction of English teaching at local area network. ICCASM 2010 - 2010 International Conference on Computer Application and System Modeling, Vol. 2, pp. 2718-2722, May 2010. https://doi.org/10.1109/iccasm.2010.5620224

[17] Q.H. Yang, Research of college English teaching based on computer network technology. Lecture Notes in Electrical Engineering, Vol. 206, pp.375-382, June 2013. https://doi.org/10.1007/978-1-4471-4790-9 48

[18] F. Zhang, M. You, Constructivism computer-assisted instruction model for college English study. Communications in Computer and Information Science, Vol. 233, pp. 200-206, February 2011. https://doi.org/10.1007/978-3-642-24010-2 27

[19] F. Zhang, Computer aided design of Chinese college English teaching materials based on COCA corpus. Applied Mechanics and Materials, Vol. 59, pp. 916-919, June 2014. https://doi.org/10.4028/www.scientific.net/AMM.651-653.916

[20] L. Zhang, Analysis on English value and the effect of computer language. IT Transactions on Engineering Sciences, Vol. 87, pp. 966-970, April 2014. https://doi.org/10.2495/amitp131181

\section{$7 \quad$ Authors}

Jingyi Bo, She received her bachelor degree of engineering in Hebei Normal University, Shijiazhuang, Hebei (2002) and master degree of engineering in Yanshan University (2008). Now she is a lecturer in College of Math and Information Science \& Technology, Hebei Normal University of Science\& Technology, Qinhuangdao, Hebei, 066004, China. Her major field of study is computer network technology. (email: qhdbjy@126.com).

Yubin Wang, He received his bachelor degree of engineering in Yanshan University, Qinhuangdao, Hebei. (2000) and master degree of engineering in Yanshan University (2009), Now he is a vice professor in College of Math and Information Science \& Technology, Hebei Normal University of Science\& Technology, Qinhuangdao, Hebei, 066004, China. His major field of study is computer network technology. (e-mail: qhdwyb@126.com).

Kun Han, She received her bachelor degree of engineering in 2000 and master degree of engineering in Yanshan University (2006). Now she is a vice professor in College of Math and Information Science \& Technology, Hebei Normal University of Science\& Technology, Qinhuangdao, Hebei, 066004, China. Her major field of study is Internet Of Things. (e-mail: hankunkun@126.com).

Article submitted 16 July 2016. Published as resubmitted by the authors 23 September 2016. 